\title{
A COMPARATIVE STUDY OF THE EFFECTS OF COLOSTRUM AND GENTAMICIN ON ORGANISMS CAUSING OPHTHALMIA NEONATORUM
}

\author{
BY \\ *EBEIGBE, J. A. AND OSAIYUWU, A. B. \\ DEPARTMENT OF OPTOMETRY, FACULTY OF LIFE SCIENCES, \\ UNIVERSITY OF BENIN, BENIN CITY, EDO STATE, NIGERIA \\ Email: jenniferebeigbe@yahoo.com \\ *Corresponding author
}

\begin{abstract}
Ophthalmia neonatorum is a form of conjunctivitis occurring in the newborn and occurs during the first 28 days of life. It can be a leading cause of blindness in newborns. This study was carried out to determine if colostrum (breast milk) has any effect on organisms implicated in ophthalmia neonatorum and to compare the effect with that of gentamicin, a commercially available antibiotic. One hundred and two samples were collected from 100 neonates with symptoms by swabbing the lower conjunctival surfaces and these swabs were analyzed microscopically. The age of the neonates ranged from birth to 10 days and mean age was 5.80days. The specimens were cultured onto pre-labeled oven dried agar plates at $37^{\circ} \mathrm{C}$ for 24 hours. The chocolate plates were incubated overnight, after which the cultured plates with growth were streaked and sub-cultured for another 24 hours at $37^{\circ} \mathrm{C}$. The agar plates without growth were further incubated for 24 hours at $37^{\circ} \mathrm{C}$, after which those with growth were sub-cultured for purification. Antibiotic susceptibility patterns were determined by using disk-diffusion tests. After culture and emergence of growth of the different microorganisms, $65.60 \%$ were found to be Staphylococcus aureus, $22.90 \%$ were Streptococcus spp, $9.40 \%$ were Escherichia coli, while $2.10 \%$ were Neisseria gonorrhea. Gentamicin inhibitory effects on causative organisms were Staphylococcus aureus 60.30\%, Streptococcus spp $72.70 \%$, Escherichia coli $100 \%$, and Neisseria gonorrhea $100 \%$. Colostrum had an inhibitory action on two of the organisms isolated (Staphylococcus aureus and Streptococcus spp) but it's action was sustained for 4 hours in about $42.20 \%$ of Staphylococcus aureus and for 6 hours in $53.30 \%$ of Streptococcus spp. Due to this short time effect of colostrum on only two of the causative organisms, it is recommended that neonates with ophthalmia neonatorum be taken to the hospital and conventional antibiotic treatment be given to them.
\end{abstract}

KEYWORDS: Staphylococcus aureus, Ophthalmia neonatorium, Colostrum, Gentamicin, Chlamydial trachomatis.

Received 03/03/2010

Accepted 24/05/2010

\section{INTRODUCTION}

Ophthalmia neonatorum, also called conjunctivitis of the newborn, refers to any conjunctivitis with discharge that occurs in the first 28 days of life ${ }^{1-5}$. The infection maybe gonococcal (caused by Neisseria gonorrhea), in which case it is potentially blinding, or nongonococcal, in which case the risk of blindness is $\operatorname{low}^{3-7}$. Chlamydia trachomatis is the most important nongonococcal etiologic agent ${ }^{8}$. Neonatal conjunctivitis is common in many developing countries ${ }^{9-10}$. It is often due to a sexually transmitted disease such as Chlamydial trachomatis and Neisseria gonorrhea ${ }^{11}$. The prevention of ophthalmia neonatorum depends considerably upon knowledge of the type and incidence of the causative organisms, as well as their sensitivity to available antimicrobial agents ${ }^{11-14}$.

The neonates conjunctiva is sterile at birth but soon becomes colonized by various organisms that may either be pathogenic or non pathogenic. The neonate's conjunctiva is prone to infection, not only because there are low levels of antibacterial agents and proteins like lysosome and immunoglobulin A and $\mathrm{G}$, but because the tear film and flow are only just beginning to develop. ${ }^{15}$

Till date the traditional practice whereby mothers instil breast milk into the eyes of their newborn infants once they notice any discharge is still being done ${ }^{16}$. Neonatal conjunctivitis presents during the first month of life and may be aseptic or 
septic. Aseptic neonatal conjunctivitis most often is chemical conjunctivitis that is induced by silver nitrate solution which is used for prophylaxis of infectious conjunctivitis. Bacterial, chlamydial, and viral infections are major causes of septic neonatal conjunctivitis, chlamydia being the most common infectious agent. Infants may acquire these infective agents as they pass through the birth canal during the birth process ${ }^{17}$.

Ophthalmia neonatorum presents with acute purulent discharge from the eyes, usually bilateral and associated with chemosis, marked hyperemia and lid edema which if left untreated, can lead to blindness through corneal ulceration and scarification $^{18}$.

\section{RESEARCH METHODOLOGY}

This was a comparative experimental study. It was a prospective study consisting of neonates from the neonatal and maternity wards of the Lagos State University Teaching hospital. Age range of neonates was birth to 10 days of life, with a mean age of 5.80days. Neonates used were known have symptomatic cases of ophthalmia neonatorum.

Eye samples of one hundred neonates with symptoms of ophthalmia neonatorum, which include discharge, conjunctiva chemosis, lid edema and hyperemia, were used for this study. Samples were collected by swabbing the lower conjunctival surfaces with sterile swabs. The swabs were labeled for the required tests and taken to the laboratory, where they were cultured onto pre-labeled oven-dried agar plates (Chocolate, Nutrient and Blood agar) at $37^{\circ} \mathrm{C}$ for 24 hours. The chocolate plates were incubated under microaerophilic conditions or anaerobic environment using $\mathrm{CO}_{2}$ jar.

After the overnight incubation, the culture plates with growth were streaked and sub-cultured for another 24 hours at $37^{\circ} \mathrm{C}$. The agar plates without growth were further incubated for 24 hours at $37^{\circ} \mathrm{C}$, after which those with growth were subcultured for purification. Using standard techniques, which included cultural, colonial morphology and biological characteristics of these isolates on the media, the isolates obtained were identified. Disc diffusion tests were used to determine the antibiotic susceptibility patterns. After culture and emergence of growth of the different microorganisms, sensitivity testing to colostrum and gentamicin was conducted on all the different organisms isolated.

For gentamicin, with the aid of a sterile wire loop a colony of each organism was picked and smeared on the surface of the oven dried nutrient agar. An antibiotic disc (gram negative) containing gentamicin was then placed on the surface of the specimen. This was incubated for 24 hours. The appearance of a clear zone showed that the organism was sensitive to the antibiotic in this case, gentamicin. The appearance of the clear zone showed that the antibiotic cleared the growth and further inhibited the activity of the organism by maintaining the clear zone. This was graded as one plus, two pluses or three pluses, depending on the area in millimeters that was inhibited. This was then recorded.

For colostrum, isolates were emulsified in $1 \mathrm{ml}$ of colostrums. With the aid of a wire loop, the medium was cultured in a nutrient agar to test for sensitivity. Inhibition or emergence of growth was the pointer. This was monitored for 2hours, 4 hours, 6hours and after 24hours. Plus (+) indicated sensitivity of organism to colostrum, while minus (-) indicated organism not sensitive to colostrum.

\section{RESULTS}

A total of one hundred and two eye samples were collected $(\mathrm{N}=102)$. Ninety six yielded growth $(94.10 \%)$ while the other six samples $(5.90 \%)$ yielded no bacteria growth.

Of the isolates, Staphylococcus aureus was the highest $(\mathrm{n}=63)$ and the lowest was Neisseria gonorrhea $(\mathrm{n}=2)$. Staphylococcus aureus had $65.60 \%$, streptococcus spp had $22.90 \%$, Escherichia coli had $9.40 \%$ while the least which was Neisseria gonorrhea had $2.10 \%$.

The sensitivity of microorganisms to gentamicin and colostrum was not normally distributed (Kolmogorov-Smirnov Z-test: $\mathrm{Z}=4.61$, $\mathrm{P}<0.05)$. The difference in sensitivity of the bacteria isolates to gentamicin and colostrums was statistically significant (Mann Whitney U-statistic: $\mathrm{U}=44.0, \mathrm{P}<0.05)$.

For all microorganisms (Staphylococcus aureus, Streptococcus spp, Escherichia coli and Neisseria gonorrhea) sensitive to gentamicin, the inhibition in growth started after 2hours of incubation of the antibiotic discs with the culture media with the bacterial isolates and lasted for 24hours. The sensitivity of bacterial isolates to gentamicin is sustained for 24hours. But for 
staphylococcus aureus and streptococcus spp, sensitivity started after 2hours of incubation and was sustained for just 4hours in $42.20 \%$ of cases while in $53.30 \%$ of the others; the onset was after 2 hours and was sustained for about 6hours. While the antimicrobial activity of gentamicin against susceptible microorganisms was sustained for 24hours, that of colostrum was sustained for only 6hours.

\section{Table 1: Total numbers of isolates}

\begin{tabular}{lrr}
\hline Organism & Number & \multicolumn{2}{c}{ Percentage (\%) } \\
\hline Bacterial growth & 96 & 94.10 \\
No bacterial growth & 6 & 5.90 \\
\hline Total & 102 & 100 \\
\hline
\end{tabular}

Table 2: Percentage organisms seen $\mathbf{n}=96$

\begin{tabular}{lrr}
\hline Organism & Number & Percentage (\%) \\
\hline Staphylococcus aureus & 63 & 65.60 \\
Streptocoøpus & 22 & 22.90 \\
Escherichia & 9 & 9.40 \\
Neisseria gonorrhea & 2 & 2.0 \\
\hline Total & 96 & 100
\end{tabular}

\section{DISCUSSION}

Out of one hundred eyes swabbed, 102 isolates were obtained. This was because some of the swab samples contained more than one causal organism. Out of this number, 96 yielded growths while 6 did not show any bacterial growth. Errors of culturing and refrigerating or even the method of sample collection might have been the reason for this.

Four organisms were isolated and Staphylococcus aureus was the highest with $65.60 \%$, this was followed by Streptococcus spp. with $22.90 \%$, Escherichia coli with $9.40 \%$ while Neisseria gonorrhea was the least with $2.10 \%$.

Maternal colostrum could not be used on individual sample swabs because of the adherent suspicion in collecting breast milk from the mothers. However, studies ${ }^{19-21}$ have shown that colostrum contain the same components in healthy mothers. Any disparity therefore could only be minimal. Colostrum had an effect on both
Staphyloccus aureus and Streptococcus spp, but this was short lived as the bacterial growth was inhibited for about 4 hours in $42.20 \%$ and 6hours in $53.30 \%$.

Colostrum is known to have antibiotic effect and immunoglobulin and this is referred to as the child's first immunity after birth ${ }^{16-19}$. However its antibiotic activity in ophthalmia neonatorum is just to suppress the infections for awhile after which the organism continues to grow ${ }^{19}$.

Gentamicin which is an aminoglycoside is an antibiotic that is more potent against gram negative than for gram positive organisms ${ }^{15-18}$. This is most truthful as its sensitivity to Escherichia coli and Neisseria gonorrhea was $100 \%$ in contrast to its sensitivity to Staphylococcus aureus (60.30\%) and Streptococcus spp $(72.70 \%)$ respectively. But it still showed a better sensitivity as its actions were for as long as 24 hours.

Olatunji ${ }^{16}$ in his work in Kaduna metropolis found out that Staphylococcus aureus was the most predominant organism with Neisseria gonorrhea being the least organism identified. In his study gentamicin had $77 \%$ sensitivity to Staphylococcus aureus and $62 \%$ sensitivity to Escherichia coli. Another study in agreement with our work is Nsanze et $a l^{15}$ who identified Staphylococcus aureus as the most predominant organism and Neisseria gonorrhea as the least predominant. This might be as a result of the low incidence of gonorrhea infections due to improved health care and public awareness ${ }^{15,16}$.

Ibhanesebhor and Otobo ${ }^{5}$ investigated the in vitro inhibition of colostrum and mature milk on organisms causing ophthalmia neonatorum. In their work they found that colostrum had less than or equal to $50 \%$ inhibition on Staphylococcus aureus and coliform organisms (Escherichia coli and Klebsiella) with a mean duration of 6hours. This is in contrast with this research, as Escherichia coli were not sensitive to colostrum at all with its sensitivity to Staphylococcus aureus being about $47.60 \%$.

Also Pishiva et $a l^{18}$ found a $9.10 \%$ development of ophthalmia neonatorum in neonates that got breast milk as prophylaxis compared to the $25.60 \%$ development of the disease on neonates that did not get any prophylaxis. They also discovered that Staphylococcus aureus was the most predominant organism present and this is in agreement with this 
work.

This work is in contrast with the work of Seiga et $a l^{2 l}$ which postulated that most organisms are resistant to gentamicin. This might be as a result of environmental differences in the different strains of organisms present. Schaller $e t a l^{20}$ in their work found that chlamydial trachomatis is the most frequent pathogen present in ophthalmia neonatorum.

Mothers should be discouraged from instilling breast milk into the eyes of their babies as its effect only masks the problem, without giving a lasting solution to it. Delay in proper treatment could exacerbate the condition, especially if it is gonococcal in origin. Corneal ulceration and scarification can result from gonococcal ophthalmia neonatorum which may eventually lead to blindness ${ }^{22,23}$. Mothers should be advised to take their babies to the hospital when they notice any type of discharge. In addition good hygiene should be maintained by the mothers, as this will go a long way in the prevention of this infection.

Table 3: Sensitivity of organisms to gentamicin

\begin{tabular}{lrr}
\hline Organism & Number & Percentage of Sensitivity \\
\hline Staphylococcus aureus & 38 & 60.30 \\
Streptococcus spp. & 16 & 72.70 \\
Escherichia coli & 9 & 100 \\
Neisseria gonorrhea & 2 & 100 \\
\hline
\end{tabular}

Iadie 4: Sensitivity or organisms to colostrums

\begin{tabular}{lrr}
\hline Organism & Number & Percentage of Sensitivity \\
\hline Staphylococcus aureus & 30 & 47.60 \\
Streptococcus spp & 12 & 54.50 \\
Escherichia coli & 0 & 0 \\
Neisseria coli & 0 & 0
\end{tabular}

\section{REFERE N C E S}

1. Assadian O., Assadian, A., Aspack, C., Hahn, D. and Koller, W. (2002): Prophylaxis of Ophthalmia Neonatorum - a Nationwide Survey of the Current Practice in Austria. Wen. Klin. Wochensch. 114(5-6): 194-9.

2. Cugaly, N. (1984): The Prevention of Ophthalmia Neonatorum: Historical Background and Current Issues. Advances Int. Maternal Child Hlth 4: 11-25.

3. Prescott, L. M., Harley, J. P. and Klein, D. A. (1999): Microbiology. $4^{\text {th }}$ Edn. McGraw-Hills Company, 780pp.

4. Goldbloom, R. B. (1994): Prophylaxis for Gonococcal and Chlamydial Ophthalmia Neonatorum. Ottawa Hlth Can, 168: 68-75.

5. Ibhanesebhor, S. E. and Otobo, E. S. (1996): In Vitro Activity of Human Milk against causative organisms of Ophthalmia Neonatorum in Benin City, Nigeria. J. Trop. Pediatr. 42(6): 327-9.

6. Jarvis, V. N., Levine, R. and Asbell, P. A. (1987): Opthalmia Neonatorum: study of a decade experience at the Mount Sinai. Br. J. Ophthalmol, 71(4):295-300.

7. Isenberg, S. J., Apt, L. and Del-Signore, M.
(2003): A double application approach to Ophthalmia Neonatorum prophylaxis. Pubmed. 87: 1449-52.

8. Isenberg, S. T., Apt, L. and Del-Signore, M. (1995): The controlled Trial of Povidoneiodine as prophylaxis against Ophthalmia Neonatorum. New Eng. J. Med, 332(9): 562-6.

9. Kanski, J. J. (1998): Clinical Ophthalmology. $3^{\text {rd }}$ Edn. Butterworth-Heinemann Int'l edn. Woburn, MA, 514pp.

10 Korhonen, H. I., Marnila, P. I. and Gill, H. S. (2000): Milk Immunoglobulins and Complement factors. Br. J. Nutr, 84: 75-80.

11. Kransy, J., Borodvanska, J. and Hruba, D. (2005): The Relationship between Chlamydial trachomatis and Chlamydial pneumonia as the cause of Neonatal Conjunctivitis. Ophthalmologica. 219(4): 223-32.

12. Kransy, J., Borodvanska, J. and Hruba, D. (2003): Chlamydial pneumonia- Etiology of Ophthalmia Neonatorum. Cesk. Slov. Oftalmol, 59(4): 240-8.

13. Laga, M., Naamara, W., Brunham, R. C., D'Costa, L. J., Nsanze, H., Piot, P., Kunimoto, D., Ndinya-Achola, J. O, Slaney, L. and 
Ronald, A. R. (1986): Single dose therapy of Gonococcal Ophthalmia Neonatorum with Ceftriaxone . New Eng. J. Med. 315(22):13825.

14. Mohile, M., Deorari, A. K., Satpathy, G., Sharma, A. and Singh, M. (2002): Microbiological study of Neonatal Conjunctivitis with special reference to Chlamydial trachomatis. India J. Ophalmol. 50(4): 295-9.

15. Nsanze, H., Dawodu, A., Usami, A., Sabarinathan, K. and Varady, E. (1996): Ophthalmia Neonatorum in United Arab Emirates. Ann. Trop. Paediatr, 16(1): 27-32.

16. Olatunji, F. O. (2004): A case control study of Ophthalmia Neonatorum in Kaduna II: causative agents and their Antibiotic sensitivity. West Afr. J. Med, 23(3): 215-20.

17. Pierce, J. M., Wada M. E., and Seal U. (1982) Ophthalmia Neonatorum in the 1980's: incidence and etiology. Br. J. Med. 2: 162-163

18. Pishva, J., Krunsy D. T., Shuny K. S. and Sabaatain G., (2000): Application of Breast Milk topically for the prevention of Neonatal
Conjunctivitis in Iran. Ann Trop Paediatr, 12(1): 15-9.

19. Ramsey, K. H., Pousen, C. E. and Motiu, P. P. (1998): The in Vitro Anti-microbial capacity of human Colostrum against Chlamydial trachomatis. J. Reprod. Immunol, 38(2):15567.

20. Schaller, U., Mino De Kasparh, H. and Schriever, S. (1997): Ophthalmia Neonatorum caused by chlamydial trachomantis: Rapid diagnosis and therapy. Ophthalmologie, 94(5):317-20.

21. Seiga, K., Shoji, T. and Sugiyama, Y. (1990): Chemoprophylaxis of Ophthalmia Neonatorum through vertical infection Evaluation of Crede's method using Ofloxacin and Gentamicin. Jpn. J. Antibiot, 43(1): 10510.

22. Vasumathy, V. (2004): Prophylaxis of Ophthalmia Neonatorum. Br. J. Ophthalmol. 88(10): 1352-5.

23. Yetman, R. and Coody, D. (1997): Conjunctivitis: a practice Guideline. J. Pediatr. Hlth Care, 11(5): 238-44. 